\title{
Editorial
}

\section{New Trends in Anterior Segment Diseases of the Eye}

\author{
Francisco Javier Romero, ${ }^{1}$ Bjørn Nicolaissen, ${ }^{2}$ and Cristina Peris-Martinez ${ }^{3}$ \\ ${ }^{1}$ Facultad de Medicina y Odontologia, Universidad Católica de Valencia "San Vicente Mártir", C/Quevedo 2, 46001 Valencia, Spain \\ ${ }^{2}$ Center for Eye Research, Department of Ophthalmology, Oslo University Hospital and University of Oslo, Pb $4956 \mathrm{Nydalen}$, \\ 0424 Oslo, Norway \\ ${ }^{3}$ Fundacion Oftalmológica del Mediterraneo, Bifurcación Pio Baroja/General Aviles, 46015 Valencia, Spain
}

Correspondence should be addressed to Francisco Javier Romero; fj.romero@ucv.es

Received 24 July 2014; Accepted 24 July 2014; Published 5 August 2014

Copyright (C) 2014 Francisco Javier Romero et al. This is an open access article distributed under the Creative Commons Attribution License, which permits unrestricted use, distribution, and reproduction in any medium, provided the original work is properly cited.

Disorders of the anterior segment of the eye are leading causes of ocular morbidity. Such conditions include dry eye conditions, infections, traumas of various types, inflammatory reactions, hereditary disorders, and cataract. For a number of these patients, the rule is a continuous progression and aggravation of symptoms. The end stage is varying degrees of visual loss with or without pain.

Despite continuous advances in ophthalmology, a number of these patients represent a challenge even in highly specialized clinics in western countries. On a worldwide basis, such conditions represent a significant public health problem. Cataract and loss of corneal transparency are still two of the most common causes of blindness worldwide [1]. While cataract is a disorder of the adult and aged population, blindness due to corneal opacities is observed in all age groups. In children, loss of corneal transparency represents the third most common cause of blindness.

During the past two decades, translational research has increased our ability to understand the pathogenesis of, and also to treat, selected disorders of the ocular surface and cornea. Although still in their shaping and improved by continuous translational and clinical research, procedures for ex vivo production of corneal and conjunctival epithelial tissue allow treatment of patients with previously untreatable corneal disorders [2, 3]. Refinement of corneal transplant procedures permits targeted intervention and replacement of opaque and nonfunctioning tissues with lamellar donor tissue $[4,5]$. By such techniques, the volume of foreign tissue with a potential for stimulation of immunoreactions is reduced as is the trauma induced by the surgical intervention.
However, there is a pronounced lack of donor corneas. In western countries, one main indication for corneal transplantation is loss of endothelial function. Ongoing research within the field of tissue engineering will provide procedures for production of transplantable layers of corneal endothelium and thereby add a new and significant tool to our treatment options [6]. Procedures for cataract surgery are continuously being advanced, accompanied by a decline in the rate of complications such as astigmatism and corneal endothelial loss with subsequent corneal hydration $[7,8]$. Due to the complexity of challenges within these areas, further progress relies to a significant extent on interaction between clinical and basic research environments. In translational research projects, extraction of information is facilitated by cooperation between clinical and basic research environments $[9,10]$. The intent is to warrant that advances in basic and clinical knowledge may serve a purpose: a better understanding of the disease pathophysiology to ensure a better disease prevention, new diagnostic procedures, and novel types of treatment including drugs, whose final end point may be preclinical or clinical testing.

\section{Francisco Javier Romero Bjørn Nicolaissen \\ Cristina Peris-Martinez}

\section{References}

[1] D. Pascolini and S. P. Mariotti, "Global estimates of visual impairment: 2010," British Journal of Ophthalmology, vol. 96, no. 5, pp. 614-618, 2012. 
[2] P. Rama, S. Matuska, G. Paganoni, A. Spinelli, M. de Luca, and G. Pellegrini, "Limbal stem-cell therapy and long-term corneal regeneration," The New England Journal of Medicine, vol. 363, no. 2, pp. 147-155, 2010.

[3] A. Shahdadfar, K. Haug, M. Pathak et al., "Ex vivo expanded autologous limbal epithelial cells on amniotic membrane using a culture medium with human serum as single supplement," Experimental Eye Research, vol. 97, no. 1, pp. 1-9, 2012.

[4] G. R. J. Melles, F. A. G. J. Eggink, F. Lander et al., "A surgical technique for posterior lameliar keratoplasty," Cornea, vol. 17, no. 6, pp. 618-626, 1998.

[5] M. Saethre and L. Drolsum, "The role of postoperative positioning after DSAEK in preventing graft dislocation," Acta Ophthalmologica, vol. 92, pp. 77-81, 2014.

[6] A. L. Sabater, A. Guarnieri, E. M. Espana, W. Li, F. Prósper, and J. Moreno-Montañés, "Strategies of human corneal endothelial tissue regeneration: regen Med," Regenerative Medicine, vol. 8, pp. 183-195, 2013.

[7] Y. He, S. Zhu, M. Chen, and D. Li, "Comparison of the keratometric corneal astigmatic power after phacoemulsification: clear temporal corneal incision versus superior scleral tunnel incision," Journal of Ophthalmology, vol. 2009, Article ID 210621, 3 pages, 2009.

[8] Y. W. Guo, J. Li, H. Song, and X. Tang, "Comparison of the retinal straylight in pseudophakic eyes with PMMA, hydrophobic acrylic, and hydrophilic acrylic spherical intraocular lens," Journal of Ophthalmology, vol. 2014, Article ID 340759, 6 pages, 2014.

[9] S. Benlloch-Navarro, I. Franco, V. Sánchez-Vallejo, D. Silvestre, F. J. Romero, and M. Miranda, "Lipid peroxidation is increased in tears from the elderly," Experimental Eye Research, vol. 115, pp. 199-205, 2013.

[10] E. Arnal, C. Peris-Martínez, J. L. Menezo, S. Johnsen-Soriano, and F. J. Romero, "Oxidative stress in keratoconus?" Investigative Ophthalmology and Visual Science, vol. 52, no. 12, pp. 85928597, 2011. 


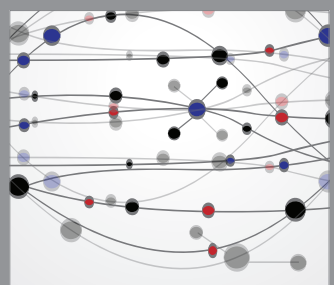

The Scientific World Journal
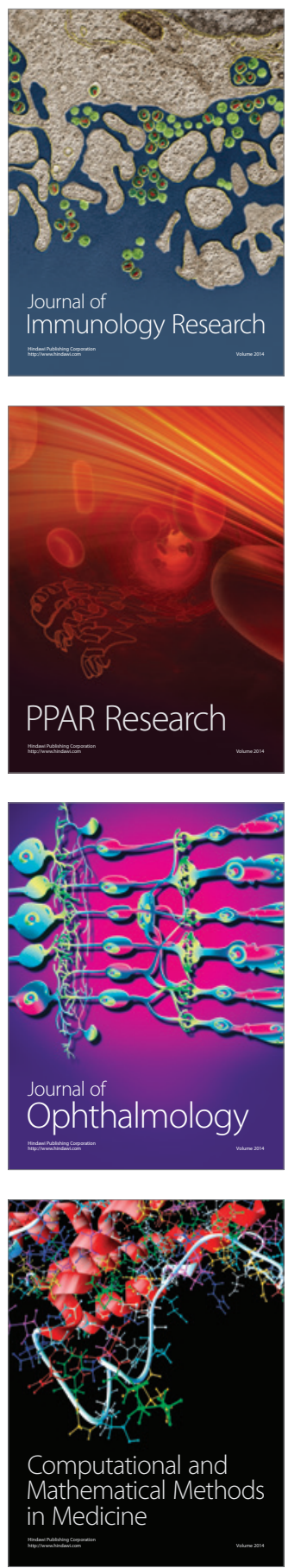

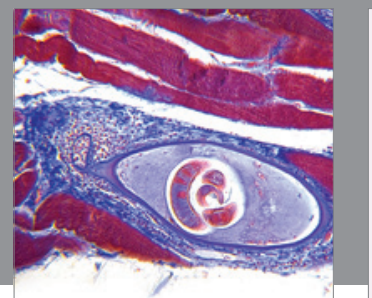

Gastroenterology

Research and Practice
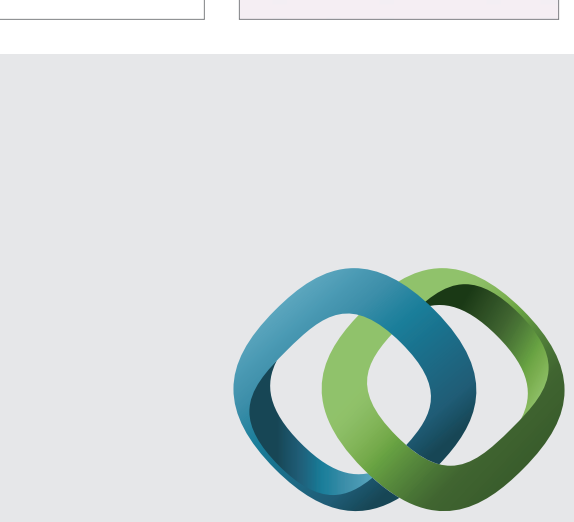

\section{Hindawi}

Submit your manuscripts at

http://www.hindawi.com
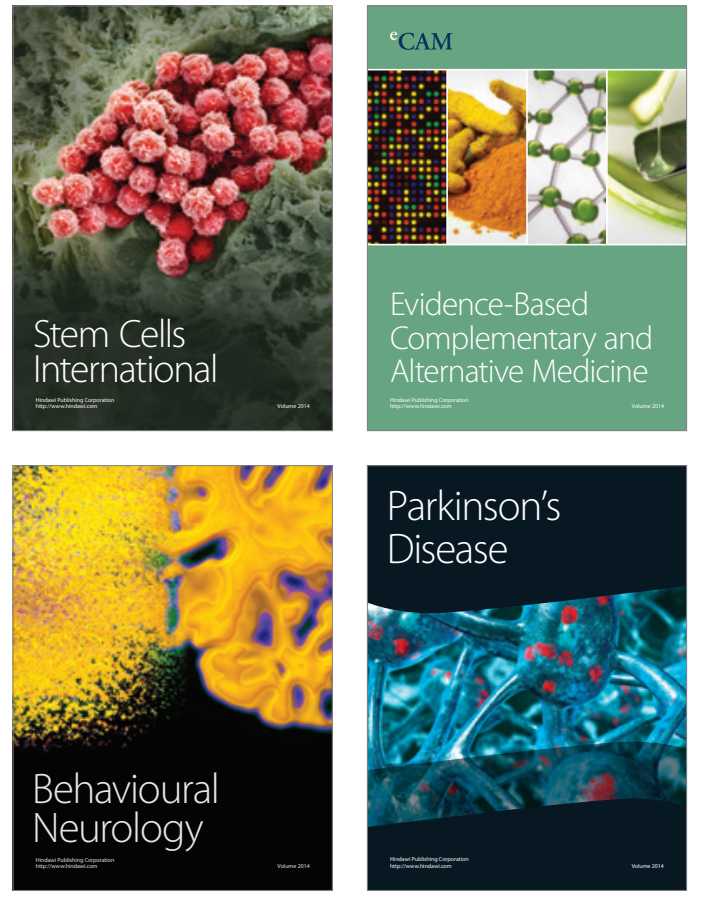
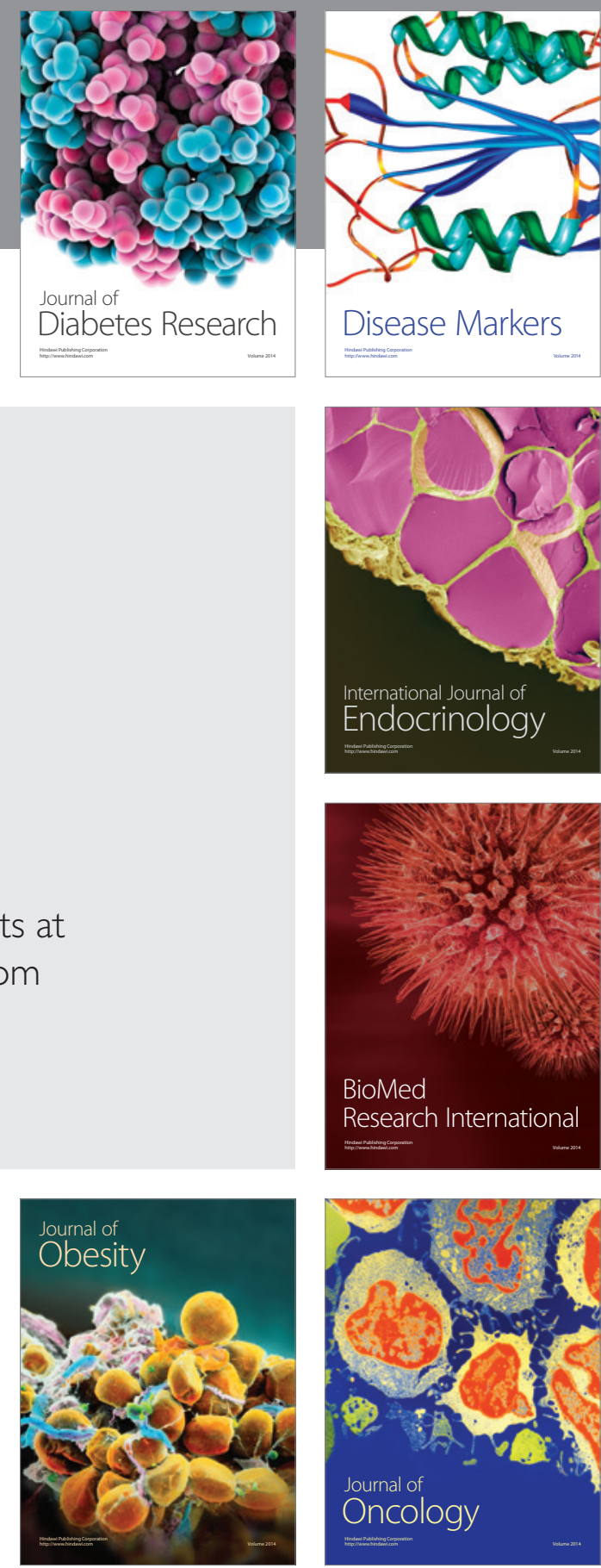

Disease Markers
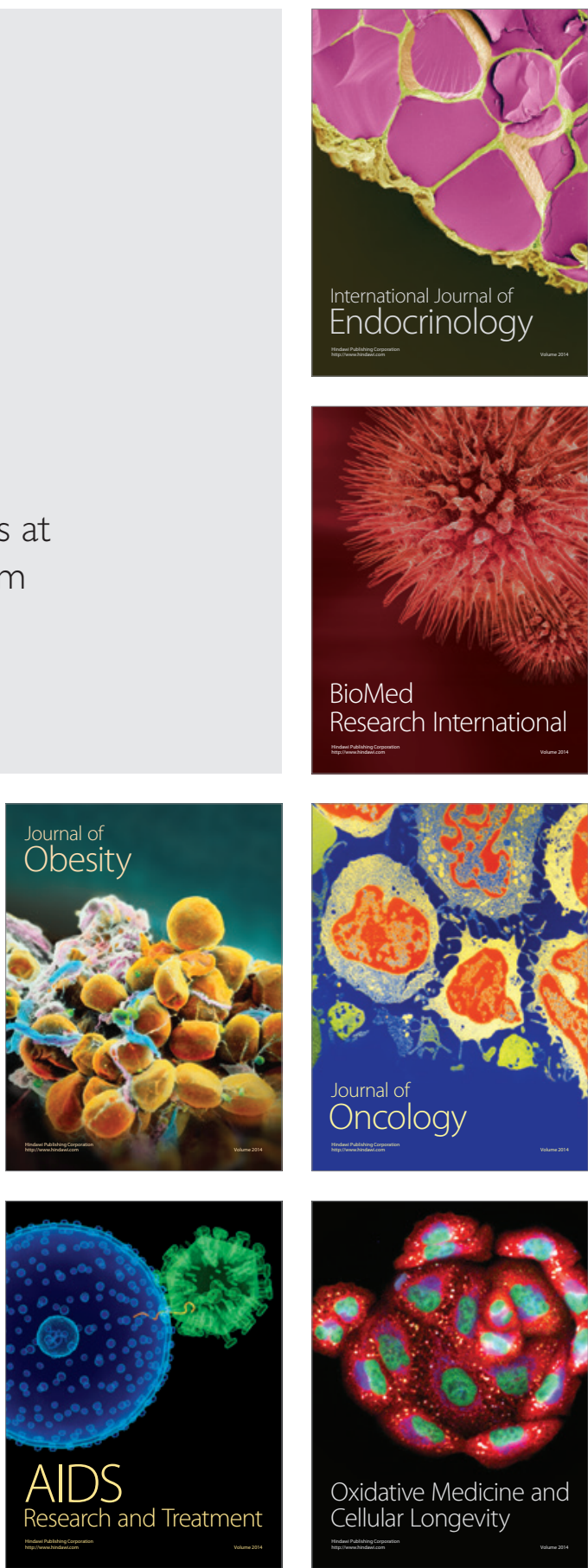